\title{
Depression and Its Determinant Factors Among University of Gondar Medical and Health Science Students, Northwest Ethiopia: Institution-Based Cross-Sectional Study
}

This article was published in the following Dove Press journal:

Neuropsychiatric Disease and Treatment

\section{Baye Dagnew (ID) \\ Henok Dagne $\mathbb{I}^{2}$ \\ Zewudu Andualem (iD) ${ }^{2}$ \\ 'Department of Human Physiology, School of Medicine, University of Gondar, Gondar, Ethiopia; ${ }^{2}$ Department of Environmental and Occupational Health and Safety, Institute of Public Health, University of Gondar, Ethiopia}

Background: Depression is a common mental disorder characterized by loss of interest or pleasure. Prevalence of depression is varied in different groups and countries. No adequate study has been undertaken in Ethiopia. This study aimed to determine the prevalence of depression and determinant factors among University of Gondar Medical and Health Sciences students, Northwest Ethiopia, 2019.

Methods: An institution-based cross-sectional study was carried out using simple random sampling technique to select study participants and the study was conducted from June to July 2019. We used self-administered second edition of Beck's Depression Inventory (BDIII) to collect data on depressive symptoms. The sample size was determined using a single population proportion formula. We entered the data using Epi Info 7 and then exported into Stata 14 for analysis. A binary logistic regression was used to identify determinant factors of depression. In the final model, a variable with a $\mathrm{p}<0.05$ was considered as a significant factor for depression by an adjustment of odds ratio with $95 \%$ of uncertainty interval (UI).

Results: Three hundred and eighty-three students completed the questionnaire with $97.7 \%$ response rate. The mean age of participants was $20.8( \pm 1.83,18-34)$ years. The prevalence of depression was $34.73 \%$ (95\% UI: 29.94-39.52\%). The odds of having depression was higher among students who came from rural family (AOR=1.67, 95\% UI: $1.02-2.72$ ), who experienced tooth grinding ( $A O R=2.79,95 \%$ UI: 1.36-5.74), who had night sleep disturbances (AOR $=1.95$, 95\% UI: $1.17-3.25)$, who reported daytime sleepiness (AOR=1.93, 95\% UI: 1.16-3.20), who had reported stress ( $\mathrm{AOR}=4.20,95 \%$ UI: $1.90-9.26)$, and those studying Health sciences (AOR=2.65, 95\% UI: 1.34-5.26).

Conclusions: The prevalence of depression among university students was high which could lead to loss of personal control, disturbed learning capacity, and social interaction. Preventive strategies such as life skills training should be given for prevention and management of depression particularly targeting students coming from a rural family, those with stress, and having poor sleep quality.

Keywords: Beck's Depression Inventory, depression, university student, Ethiopia

\section{Background}

Depression is a common mental disorder affecting above 350 million people globally and is characterized by sadness, loss of interest or pleasure, feelings of guilt or low self-worth, disturbed sleep or appetite, feelings of tiredness and poor concentration. ${ }^{1}$ The impact of depression is substantial on individual and the 
country at large due to disturbed daily life. ${ }^{2}$ The possible causes of depression can be altered neurotransmission, hypothalamic-hypophyseal-adrenal axis abnormalities involved in chronic stress, inflammation, reduced neuroplasticity, ${ }^{3}$ reduced levels of neurotrophic factors, and glutamate-mediated toxicity. ${ }^{4}$ Any situation which activates cortisol secretion may lead to depression because cortisol has a neurotoxic effect directly and indirectly through its hyperglycemic effect. ${ }^{5}$ Amygdala, hippocampus and thalamus are the main brain areas affected by depression and there are disruptions in amount and function of neurotransmitters like acetylcholine, dopamine, norepinephrine, glutamate and gammaaminobutyric acid. ${ }^{6}$

The prevalence of depression is inconsistent in different countries and study population. The pooled estimate of depression among university students in Iran was $33 \%{ }^{7}$ It was $35.7 \%$ among Kenyan students, ${ }^{8}$ and $32.2 \%$ in Nigerian students. ${ }^{9}$ Few studies in Ethiopia reported a lower prevalence of the condition as evidenced in Adama University students $(21.6 \%),{ }^{10}$ and in Awassa University students $(23.6 \%) .{ }^{11}$ A review of studies on depression among different population groups in Ethiopia estimated an $11 \%$ pooled prevalence of depression which was associated with sex, age, and marital status. ${ }^{12}$ Depression is higher among females and those with lower educational status. ${ }^{13,14}$

Although various studies on depression have been conducted, the possible determinant factors of depression among university students in Ethiopia had not been fully addressed. Thus, the current study aimed to determine the prevalence of depression and its determinant factors among University of Gondar Medical and Health Sciences students, Northwest Ethiopia, 2019.

\section{Methods}

\section{Study Design, Period, and Setting}

An institution-based cross-sectional study design was employed at the University of Gondar Medical and Health Sciences faculty from June to July 2019. University of Gondar is found in Gondar city, Northwest Ethiopia and serving above 5 million people in the catchment area since 1954 of its establishment. Currently, the University of Gondar is dedicated to teaching and learning, problemsolving activities in the community and researching different thematic areas congruent with Ethiopian Ministry of science and higher education.

\section{Population and Eligibility Criteria}

We took all of the University of Gondar Medical and Health Sciences students enrolled in the learning process for the 2019 academic calendar as a source population. All regular University of Gondar Medical and Health Sciences students who were present at the time of data collection were included as the study population. As an exclusion criteria; we excluded those students who had severe illness at the time of data collection.

\section{Sample Size Determination and Sampling Technique}

We calculated sample size (n) using a single population proportion formula by assuming the prevalence of depression $(\mathrm{P}=41.3 \%),{ }^{8} 95 \% \mathrm{UI}(\mathrm{Z} \alpha=$ standard normal variate for the level of significance), margin of error $(d)=0.05$. The minimum sample size was found to be 373. After adding a possible non-response rate of $5 \%$, the final sample size became 392. Study participants were selected using a simple random sampling technique.

\section{Data Collection Instrument, Procedure and Quality Control}

We used self-administered semi-structured questionnaire to collect the required data. The questionnaire enclosed sociodemographic characteristics of participants, Epworth daytime sleepiness screening variables, perceived stress scale to assess stress, night sleep behaviour disorder and depression assessment scales. We used Beck's depression inventory second edition (BDI-II) for collecting variables regarding depression and it is composed of 21 questions, each question with four possible responses. For each response a score ranging from zero to three was assigned, indicating the severity of a symptom. The overall value of a scale ranges from zero to $63 .{ }^{15}$ We collected variables related to daytime sleepiness, night sleep behaviour disorder and stress using Epworth day time sleepiness screening, ${ }^{16}$ Rapid eye movement sleep behaviour disorder screening tool $^{17}$ and perceived stress scale ${ }^{18}$ respectively. We recruited two MSc Physiology students as facilitators and orientation was given for them on how to distribute and instruct students to fill the questionnaire and to return it. A pre-test was done on 30 students to check for grammar flow and consistency. Necessary corrections were made after the pre-test results.

\section{Study Variables}

Dependent variable: Depression 
Independent variables: Age in years, monthly income in Ethiopian birr, year of study, Khat chewing, cigarette smoking, alcohol intake, coffee consumption, tooth grinding, sleep disorders, field of study, and stress.

\section{Operational/Term Definitions}

Depression: We used the second edition of Beck's depression inventory (BDI-II) revised in 1996. When a person scored 21 and above from the total of 63 scores of BDI-II, he/she had depression. ${ }^{19}$

Stress: We considered a person as having stress when he/she scored 5 and above of the total (40 scores) of the 10 item questions of perceived stress scale (PSS-10). ${ }^{20}$

Excessive daytime sleepiness: We asked eight items, each with three alternatives, to assess daytime sleepiness. We categorized a person as having excessive daytime sleepiness when he/she scored 11 and above from the total score of $24 .^{21}$

\section{Reliability}

We computed Cronbach's alpha to test reliability (internal consistency) of the tool for the assessment of depression with alpha value of 0.86 which is good. We also found a scale reliability coefficient of 0.7 for night sleep behavior disorder screening questionnaire, 0.79 for perceived stress scale, and 0.725 for daytime sleepiness assessment tool all of which are acceptable according to Mallery. ${ }^{22}$

\section{Data Management and Statistical Analysis}

After completing coding of variables, the authors used Epi info ${ }^{\mathrm{TM}}$ version 7.1 for data entry and then exported into Stata 14 for cleaning, processing, and statistical inferences of the data. Frequency with percent for categorical variables, and mean with standard deviation were calculated to describe results for continuous variables. Point prevalence and interval prevalence with $95 \%$ uncertainty was calculated for depression. We performed logistic regression analysis to identify determinant factors of depression. Variables in bivariable analysis with a p-value of less than 0.2 were nominated for multivariable logistic regression. In the final model (multivariable logistic regression model), odd ratios with $95 \%$ UI were computed and variables with a p-value $<0.05$ were considered to be significantly associated with depression.

\section{Results}

\section{Descriptive Characteristics of Study Participants}

Three hundred and eighty-three students (male $=268$, female $=115$ ) took part in the study with $97.7 \%$ response rate. The mean age of participants was $20.8( \pm 1.83$, range 18-34) years. Of the total participants; 319 (83.29\%) were orthodox Christian followers, 235 (61.36\%) were secondyear and above, 302 (78.85\%) were studying Health sciences, and 224 (58.49\%) came from the urban area (preuniversity residence). Two hundred and seventy-six $(72.06 \%)$ students engaged in a romantic relationship, and $47(12.27 \%)$ participants experienced involuntary tooth grinding at night. We found 177 (46.21\%) students experiencing self-reported night sleep behaviour disorder, 119 (31.07\%) had daytime sleepiness, and 311 (81.20\%) reported stress (Table 1).

\section{Prevalence of Depression Among University Students}

In this study, the prevalence of depression was 34.73\% (95\% UI: 29.94-39.52\%). Ninety-six males and 37 females had self-reported depressive symptoms. Eightysix students who came from rural family and 119 Health science students had self-reported depression.

\section{Determinant Factors of Depression Among University Students}

We had performed binary logistic regression to check the simple association between each exposure variable and depression. Of those variables tested in bivariable analysis; engagement in romantic friendship, pre-university residence, vivid dreaming at night, involuntary tooth grinding at night (bruxism), age, night sleep disturbance, daytime sleepiness, the field of study, and self-reported stress had a $\mathrm{p}<0.2$. Therefore, the aforementioned variables were entered into the multivariable logistic regression. In the final model; rural pre-university residence ( $\mathrm{AOR}=1.67,95 \%$ UI: $1.02-2.72)$, involuntary tooth grinding $(\mathrm{AOR}=2.79,95 \% \mathrm{UI}: 1.36-5.74)$, experiencing self-reported night sleep disturbance (AOR $=1.95,95 \%$ UI: $1.17-3.25$ ), be subjected to daytime sleepiness (AOR $=1.93,95 \%$ UI: $1.16-3.20)$, having stress ( $\mathrm{AOR}=4.20,95 \%$ UI: 1.90-9.26), and studying Health sciences ( $\mathrm{AOR}=2.65,95 \%$ UI: $1.34-5.26)$ were significantly associated with depression (Table 2). 
Table I Sociodemograpic and Self-Reported Neurological Characteristics of Study Participants at the University of Gondar, Northwest Ethiopia, 2019 ( $n=383)$

\begin{tabular}{|c|c|c|c|}
\hline Variables & Categories & Frequency & $\begin{array}{l}\text { Percent } \\
\text { (\%) }\end{array}$ \\
\hline Sex & $\begin{array}{l}\text { Male } \\
\text { Female }\end{array}$ & $\begin{array}{l}268 \\
115\end{array}$ & $\begin{array}{l}69.97 \\
30.03\end{array}$ \\
\hline Religion & $\begin{array}{l}\text { Orthodox } \\
\text { Muslim } \\
\text { Protestant } \\
\text { Catholic }\end{array}$ & $\begin{array}{l}319 \\
24 \\
35 \\
5\end{array}$ & $\begin{array}{l}83.29 \\
6.27 \\
9.14 \\
1.31\end{array}$ \\
\hline Year of study & $\begin{array}{l}\text { First-year } \\
\text { Second-year } \\
\text { and above }\end{array}$ & $\begin{array}{l}148 \\
235\end{array}$ & $\begin{array}{l}38.64 \\
61.36\end{array}$ \\
\hline $\begin{array}{l}\text { Engaged in romantic } \\
\text { friendship }\end{array}$ & $\begin{array}{l}\text { No } \\
\text { Yes }\end{array}$ & $\begin{array}{l}276 \\
107\end{array}$ & $\begin{array}{l}72.06 \\
27.94\end{array}$ \\
\hline $\begin{array}{l}\text { Pre-university } \\
\text { residence }\end{array}$ & $\begin{array}{l}\text { Urban } \\
\text { Rural }\end{array}$ & $\begin{array}{l}224 \\
159\end{array}$ & $\begin{array}{l}58.49 \\
41.51\end{array}$ \\
\hline $\begin{array}{l}\text { Vivid dreaming at } \\
\text { night }\end{array}$ & $\begin{array}{l}\text { No } \\
\text { Yes }\end{array}$ & $\begin{array}{l}107 \\
276\end{array}$ & $\begin{array}{l}27.94 \\
72.06\end{array}$ \\
\hline $\begin{array}{l}\text { Bruxism (tooth } \\
\text { grinding) }\end{array}$ & $\begin{array}{l}\text { No } \\
\text { Yes }\end{array}$ & $\begin{array}{l}336 \\
47\end{array}$ & $\begin{array}{l}87.73 \\
12.27\end{array}$ \\
\hline Age in years & $\begin{array}{l}20 \text { years and } \\
\text { below } \\
21 \text { years and } \\
\text { above }\end{array}$ & $\begin{array}{l}197 \\
186\end{array}$ & $\begin{array}{l}51.44 \\
48.56\end{array}$ \\
\hline $\begin{array}{l}\text { Night sleep } \\
\text { disturbance }\end{array}$ & $\begin{array}{l}\text { No } \\
\text { Yes }\end{array}$ & $\begin{array}{l}206 \\
177\end{array}$ & $\begin{array}{l}53.79 \\
46.21\end{array}$ \\
\hline Daytime sleepiness & $\begin{array}{l}\text { No } \\
\text { Yes }\end{array}$ & $\begin{array}{l}264 \\
119\end{array}$ & $\begin{array}{l}68.93 \\
31.07\end{array}$ \\
\hline Stress & $\begin{array}{l}\text { No } \\
\text { Yes }\end{array}$ & $\begin{array}{l}72 \\
311\end{array}$ & $\begin{array}{l}18.80 \\
81.20\end{array}$ \\
\hline Field of study & $\begin{array}{l}\text { Medicine } \\
\text { Health sciences }\end{array}$ & $\begin{array}{l}81 \\
302\end{array}$ & $\begin{array}{l}21.15 \\
78.85\end{array}$ \\
\hline
\end{tabular}

\section{Discussion}

The current study aimed at investigating the magnitude and possible determinant factors of depression among University of Gondar students. The prevalence of depression was 34.73\% at $95 \%$ (UI $=29.94-39.52 \%$ ) which is the major Public Health problem. This is consistent with previously published studies as evidenced in Iran $(33 \%){ }^{7}$ India $(37.7 \%),{ }^{23}$ Malaysia $(37.2 \%),{ }^{24}$ Ghana $(39.2 \%),{ }^{25}$ global pooled estimate $(30.6 \%),{ }^{26}$ and Nigeria $(32.2 \%){ }^{9}$ However, other studies such as in Turkey $(27.1 \%){ }^{14}$ global pooled prevalence $(27.2 \%),{ }^{27}$ and another study in Turkey $21.8 \%,{ }^{28}$ Oman
$(27.7 \%),{ }^{29}$ and China $(11.7 \%)^{30}$ reported a lower prevalence of depression than the current study. Few studies in Ethiopia reported a lower magnitude of depression as revealed in Adama (21.6\%), ${ }^{10}$ and Awassa (23.6\%). ${ }^{11}$ This difference could be because of variations in the instrument used to measure depression (a study in Adama used self-reporting questionnaire (SRQ-20) and the study in Awassa used Patient Health questionnaire (PHQ-9), and sample size (sample size for the study in Awassa was 1176, and 413 in Adama) and the learning environment and academic culture. In contrary, the prevalence of depression in the current study was lower than previously published studies from Fayoum University $(60.8 \%),{ }^{31}$ Alexandria University $(57.9 \%),{ }^{32}$ and Kenya $(41.3 \%) .{ }^{8}$ This might be due to differences in the data collection tool used to measure depression, sample size and the academic culture in universities.

Students coming from rural family were 1.67 times more likely to develop depression. This is supported by previously published studies as in Columbia, ${ }^{33}$ Britain, ${ }^{34}$ and China. ${ }^{35}$ The reason for this association might be due to economic deprivation in the rural society and those students from rural family may face financial constraint which could lead students get depressed. ${ }^{36}$ The odds of having depression is 2.79-fold among students who experienced involuntary tooth grinding and it is supported by another study. ${ }^{37}$ This might be because students with involuntary tooth grinding are more likely to get stress and the pathogenesis of depression and stress share similar mechanisms. Stress-induced cortisol production could lead to depression. ${ }^{38,39}$ The odds of getting depression is 1.95 fold among students who experienced self-reported night sleep behaviour disorder than those without sleep disorder which is propped by other studies. ${ }^{40,41}$ This association could be because "when sleep pathways are affected, there will be production of neurotransmitters and hormones to increase depression". ${ }^{42,43}$ Students who had self-reported stress were 4.2 times more likely to get depressed than those without stress which is supported by a previous study. ${ }^{44}$ The biological link to this association can be explained by many scholars in that stress-induced chemicals such as dynorphin, catecholamines and others are responsible for the pathogenesis of depressive symptoms. ${ }^{45}$ Besides the above determinant factors of depression, students who were studying Health sciences were more likely to develop depression than those who were studying Medicine. There is no such study that compared Medical and Health sciences students regarding depression but the association could be because most 
Table 2 Associated Factors of Depression Among Participants Using Multivariable Logistic Regression, University of Gondar ( $\mathrm{n=383)}$

\begin{tabular}{|c|c|c|c|c|c|}
\hline \multirow[t]{2}{*}{ Variables } & \multirow[t]{2}{*}{ Categories } & \multicolumn{2}{|c|}{ Depression } & \multirow[t]{2}{*}{ COR (95\% UI) } & \multirow[t]{2}{*}{ AOR (95\% UI) } \\
\hline & & No (\%) & Yes (\%) & & \\
\hline \multirow[t]{2}{*}{ Engaged in romantic friendship } & No & 186(67.39) & $90(32.61)$ & I & I \\
\hline & Yes & $64(59.81)$ & $43(40.19)$ & $1.39(0.88-2.20)$ & $0.91(0.53-1.55)$ \\
\hline \multirow[t]{2}{*}{ Pre-university residence } & Urban & $164(73.21)$ & $60(26.79)$ & 1 & I \\
\hline & Rural & $86(54.09)$ & $73(45.91)$ & $2.32(1.5 \mathrm{I}-3.57)$ & $1.67(1.02-2.72)^{*}$ \\
\hline \multirow[t]{2}{*}{ Vivid dreaming at night } & No & $80(74.77)$ & $27(25.23)$ & I & I \\
\hline & Yes & $170(6 \mid .59)$ & $106(38.41)$ & $1.85(1.12-3.04)$ & $\mathrm{I} .55(0.85-2.8 \mathrm{I})$ \\
\hline \multirow[t]{2}{*}{ Bruxism(tooth grinding) } & No & $229(68.15)$ & $107(31.85)$ & I & I \\
\hline & Yes & $21(44.68)$ & $26(55.32)$ & $2.65(1.43-4.92)$ & $2.79(1.36-5.74)^{* *}$ \\
\hline Age in years & & \multicolumn{2}{|c|}{ Mean $\pm S D=20.79 \pm 1.83$} & $1.18(1.05-1.33)$ & $1.08(0.94-1.24)$ \\
\hline \multirow[t]{2}{*}{ Night sleep disturbance } & No & $160(77.67)$ & $46(22.33)$ & I & I \\
\hline & Yes & $90(50.85)$ & $87(49.15)$ & $3.36(2.16-5.22)$ & $1.95(1.17-3.25)^{*}$ \\
\hline \multirow[t]{2}{*}{ Daytime sleepiness } & No & $188(7 \mid .21)$ & $76(28.79)$ & I & I \\
\hline & Yes & $62(52.10)$ & $57(47.90)$ & 2.27 (I.45-3.59) & $1.93(1.16-3.20)^{*}$ \\
\hline \multirow[t]{2}{*}{ Stress } & No & $63(87.5)$ & $9(12.5)$ & I & I \\
\hline & Yes & $187(60.13)$ & $124(39.87)$ & $4.64(2.23-9.67)$ & $4.20(1.90-9.26)^{* * *}$ \\
\hline \multirow[t]{2}{*}{ Field of study } & Medicine & $67(82.72)$ & |4(17.28) & I & I \\
\hline & Health sciences & $183(60.60)$ & $119(39.40)$ & $3.11(1.67-5.79)$ & $2.65(1.34-5.26)^{* *}$ \\
\hline
\end{tabular}

Notes: I=reference (indicator). *significant at $\mathrm{p}<0.05$, **significant at $\mathrm{p}<0.0 \mathrm{I}$, ***significant at $\mathrm{p}<0.00 \mathrm{I}$, Hosmer-Lemshow goodness-of-fit test $(\mathrm{p}=0.075)$.

Abbreviation: UI, Uncertainty interval.

Health science students' interest is to study Medicine and because of missing their first department choice they may get depressed.

\section{Conclusions}

In the current study, the prevalence of depression among university students was high. The higher existence of depression could reduce the quality of life, results in loss of personal control, disturbed learning capacity, and social interaction which might end up with lower productivity, decreased academic performance and, suicidal attempt. To enhance students performance and social interaction with their friends or the surrounding population, the governmental and nongovernmental organizations have to design strategies for prevention and management of depression particularly targeting students coming from a rural family, those with stress, and having sleep problems. Strategies may include delivering life skill training to cope up with the environmental factors affecting their day to day life.

\section{Limitations of the Study}

A BDI-II questionnaire is a screening tool which cannot show the real presence of depression. The study could not infer the cause and effect relationship and recall bias was also be a possible limitation. The study was a snapshot that we were not able to assess the outcomes of depression on academic performance of students.

\section{Abbreviations}

AOR, Adjusted Odds Ratio; COR, Crude Odds Ratio; UI, Uncertainty Interval; BDI-II, Beck's Depression Inventory version II; EPI Info, Epidemiological Information.

\section{Data Sharing Statement}

The dataset is available and can be obtained from the corresponding author upon reasonable request.

\section{Ethics and Consent Statement}

We secured ethical approval letter from the Department of Environmental and occupational health and safety, University of Gondar. After preparing information sheet about the study significance and ethical issues, we gave the written consent form to each participant and asked them to sign if they are willing to take part in the study. So written informed consent was obtained from each study participant before proceeding the data collection process. No 
names or any probable identifiers were written to maintain confidentiality. So the ethical approval was in accordance with the declaration of Helsinki.

\section{Acknowledgments}

The authors' would like to gratitude study participants, University of Gondar, and facilitators.

\section{Author Contributions}

All authors contributed to data analysis, drafting or revising the article, gave final approval of the version to be published, and agree to be accountable for all aspects of the work.

\section{Funding}

No funding was obtained for conducting this research work.

\section{Disclosure}

The authors declare that they have no competing interests.

\section{References}

1. Marcus M, Mark van Ommeren MY, Dan Chisholm, et al. Depression: A global public health concern; 2012. Available from: https://www.researchgate.net/publication/285075782_Depression_A_ global_public_health_concern. Accessed February 3, 2020.

2. Sager R. The burden of mental disorders across the states of India: the Global Burden of Disease Study 1990-2017. Lancet Psychiatry. 2020;7(2):148-161. doi:10.1016/S2215-0366(19)30475-4

3. Dean J, Keshavan M. The neurobiology of depression: an integrated view. Asian J Psychiatr. 2017;27:101-111. doi:10.1016/j. ajp.2017.01.025

4. Mahajan GJ, Vallender EJ, Garrett MR, et al. Altered neuro-inflammatory gene expression in hippocampus in major depressive disorder. Prog Neuropsychopharmacol Biol Psychiatry. 2018;82:177-186. doi:10.1016/j.pnpbp.2017.11.017

5. Qin D-D, Rizak J, Feng X-L, et al. Prolonged secretion of cortisol as a possible mechanism underlying stress and depressive behaviour. Sci Rep. 2016;6(1):30187. doi:10.1038/srep30187

6. Publishing HH What causes depression? June 24 2019; Available from: https://www.health.harvard.edu/mind-and-mood/what-causesdepression. Accessed March 24, 2020.

7. Sarokhani D, Delpisheh A, Veisani Y, et al. Prevalence of depression among university students: a systematic review and meta-analysis study. Depress Res Treat. 2013;2013.

8. Othieno CJ, Okoth RO, Peltzer K, et al. Depression among university students in Kenya: prevalence and sociodemographic correlates. J Affect Disord. 2014;165:120-125. doi:10.1016/j.jad.2014.04.070

9. Peltzer K, Pengpid S, Olowu S, et al. Depression and associated factors among university students in Western Nigeria. J Psychol Africa. 2013;23(3):459-465. doi:10.1080/14330237.2013.10820652

10. Dessie Y, Ebrahim J, Awoke T. Mental distress among university students in Ethiopia: a cross sectional survey. Pan African Med J. 2013;15(1). doi:10.11604/pamj.2013.15.95.2173

11. Terasaki DJ, Gelaye B, Berhane Y, Williams MA. Anger expression, violent behavior, and symptoms of depression among male college students in Ethiopia. BMC Public Health. 2009;9(1):13.
12. Bitew T. Prevalence and risk factors of depression in Ethiopia: a review. Ethiop J Health Sci. 2014;24(2):161-169. doi:10.4314/ejhs. v24i2.9

13. Yeshaw Y, Mossie A. Depression, anxiety, stress, and their associated factors among Jimma University staff, Jimma, Southwest Ethiopia, 2016: a cross-sectional study. Neuropsychiatr Dis Treat. 2017;13:2803. doi:10.2147/NDT.S150444

14. Bayram N, Bilgel N. The prevalence and socio-demographic correlations of depression, anxiety and stress among a group of university students. Soc Psychiatry Psychiatr Epidemiol. 2008;43(8):667-672. doi:10.1007/s00127-008-0345-x

15. Beck AT, Steer RA, Brown GK. Beck depression inventory-II. San Antonio. 1996;78(2):490-498.

16. Johns MW. A new method for measuring daytime sleepiness: the Epworth sleepiness scale. Sleep. 1991;14(6):540-545. doi:10.1093/ sleep/14.6.540

17. Stiasny-Kolster K, Mayer G, Schäfer S, Möller JC, HeinzelGutenbrunner M, Oertel WH. The REM sleep behavior disorder screening questionnaire - a new diagnostic instrument. Mov Disorders. 2007;22(16):2386-2393. doi:10.1002/mds.21740

18. Cohen S, Kamarck T, Mermelstein R. Perceived Stress Scale. Measuring Stress: A Guide for Health and Social Scientists. New York: Oxford University; 1994:235-283.

19. Duko B, Erdado M, Ebrahim J. Prevalence and factors associated with depression among hospital admitted patients in South Ethiopia: cross sectional study. BMC Res Notes. 2019;12(1):73. doi:10.1186/ s13104-019-4109-3

20. Cohen S, Kamarck T, Mermelstein R. Perceived Stress Scale. Measuring Stress: A Guide for Health and Social Scientists. New York: Oxford University Press; 1994:10.

21. Johns MW. Reliability and factor analysis of the Epworth Sleepiness Scale. Sleep. 1992;15(4):376-381. doi:10.1093/sleep/15.4.376

22. Mallery P, George D. SPSS for Windows Step by Step: A Simple Guide and Reference. Bacon, Boston: Allyn; 2003.

23. Deb S, Banu PR, Thomas S, et al. Depression among Indian university students and its association with perceived university academic environment, living arrangements and personal issues. Asian J Psychiatr. 2016;23:108-117. doi:10.1016/j.ajp.2016.07.010

24. Shamsuddin K, Fadzil F, Ismail WSW, et al. Correlates of depression, anxiety and stress among Malaysian university students. Asian J Psychiatr. 2013;6(4):318-323. doi:10.1016/j.ajp.2013.01.014

25. Asante KO, Andoh-Arthur J. Prevalence and determinants of depressive symptoms among university students in Ghana. $J$ Affect Disord. 2015;171:161-166. doi:10.1016/j.jad.2014.09.025

26. Ibrahim AK, Kelly SJ, Adams CE, et al. A systematic review of studies of depression prevalence in university students. J Psychiatr Res. 2013;47(3):391-400. doi:10.1016/j.jpsychires.2012.11.015

27. Rotenstein LS, Ramos MA, Torre M, et al. Prevalence of depression, depressive symptoms, and suicidal ideation among medical students: a systematic review and meta-analysis. JAMA. 2016;316 (21):2214-2236. doi:10.1001/jama.2016.17324

28. Arslan G, Ayranci U, Unsal A, et al. Prevalence of depression, its correlates among students, and its effect on health-related quality of life in a Turkish university. Ups J Med Sci. 2009;114(3):170-177. doi:10.1080/03009730903174339

29. Al-Busaidi Z, Bhargava K, Al-Ismaily A, et al. Prevalence of depressive symptoms among university students in Oman. Oman Med J. 2011;26(4):235. doi:10.5001/omj.2011.58

30. Chen L, Wang L, Qiu XH, et al. Depression among Chinese university students: prevalence and socio-demographic correlates. PLoS One. 2013;8(3):e58379. doi:10.1371/journal.pone.0058379

31. Wahed WYA, Hassan SK. Prevalence and associated factors of stress, anxiety and depression among medical Fayoum University students. Alexandria Journal of Medicine. 2017;53(1):77-84. doi:10.1016/j. ajme.2016.01.005 
32. Ibrahim MB, Abdelreheem MH. Prevalence of anxiety and depression among medical and pharmaceutical students in Alexandria University. Alexandria Journal of Medicine. 2015;51(2):167-173. doi:10.1016/j.ajme.2014.06.002

33. Probst JC, Laditka SB, Moore CG, Harun N, Powell MP, Baxley EG. Rural-urban differences in depression prevalence: implications for family medicine. Family Med Kansas City. 2006;38(9):653.

34. Walters K, Breeze E, Wilkinson P, et al. Local area deprivation and urban-rural differences in anxiety and depression among people older than 75 years in Britain. Am J Public Health. 2004;94 (10):1768-1774. doi:10.2105/AJPH.94.10.1768

35. Li LW, Liu J, Xu H, et al. Understanding rural-urban differences in depressive symptoms among older adults in China. J Aging Health. 2016;28(2):341-362. doi:10.1177/0898264315591003

36. Rost K, Zhang M, Fortney J, et al. Rural-urban differences in depression treatment and suicidality. Med Care. 1998;36(7):1098-1107. doi:10.1097/00005650-199807000-00015

37. Gungormus Z, Erciyas K. Evaluation of the relationship between anxiety and depression and bruxism. J Intl Med Res. 2009;37 (2):547-550. doi:10.1177/147323000903700231

38. Cavallo P, Carpinelli L, Savarese G. Perceived stress and bruxism in university students. BMC Res Notes. 2016;9(1):514. doi:10.1186/ s13104-016-2311-0

39. Quadri MFA, Mahnashi A, Al Almutahhir A, et al. Association of awake bruxism with khat, coffee, tobacco, and stress among Jazan university students. Int J Dent. 2015;2015.
40. Baglioni C, Nanovska S, Regen W, et al. Sleep and mental disorders: A meta-analysis of polysomnographic research. Psychol Bull. 2016;142(9):969-990. doi:10.1037/bul0000053

41. Weaver MD, Vetter C, Rajaratnam SMW, et al. Sleep disorders, depression and anxiety are associated with adverse safety outcomes in healthcare workers: A prospective cohort study. J Sleep Res. 2018;27(6):e12722-e12722. doi:10.1111/jsr.2018.27.issue-6

42. Foundation NS. Depression and Sleep; 2019. Available from: https:// www.sleepfoundation.org/articles/depression-and-sleep. Accessed March 24, 2020.

43. Baglioni C, Spiegelhalder K, Nissen C, et al. Clinical implications of the causal relationship between insomnia and depression: how individually tailored treatment of sleeping difficulties could prevent the onset of depression. EPMA J. 2011;2(3):287-293. doi:10.1007/ s13167-011-0079-9

44. Slavich GM, Irwin MR. From stress to inflammation and major depressive disorder: a social signal transduction theory of depression. Psychol Bull. 2014;140(3):774-815. doi:10.1037/ a0035302

45. Knoll AT, Carlezon Jr WA. Dynorphin, stress, and depression. Brain Res. 2010;1314(p):56-73. doi:10.1016/j.brainres.2009.09.074
Neuropsychiatric Disease and Treatment

\section{Publish your work in this journal}

Neuropsychiatric Disease and Treatment is an international, peerreviewed journal of clinical therapeutics and pharmacology focusing on concise rapid reporting of clinical or pre-clinical studies on a range of neuropsychiatric and neurological disorders. This journal is indexed on PubMed Central, the 'PsycINFO' database and CAS, and

\section{Dovepress}

is the official journal of The International Neuropsychiatric Association (INA). The manuscript management system is completely online and includes a very quick and fair peer-review system, which is all easy to use. Visit http://www.dovepress.com/testimonials.php to read real quotes from published authors. 